\title{
Correction to: After-effects of self-control: The reward responsivity hypothesis
}

\author{
Nicholas J. Kelley ${ }^{1} \cdot$ Anna J. Finley ${ }^{2} \cdot$ Brandon J. Schmeichel $^{2}$
}

Published online: 20 February 2019

(C) The Psychonomic Society, Inc. 2019

\section{Correction to: Cogn Affect Behav Neurosci https://doi.org/10.3758/s13415-019-00694-3}

The article After-effects of self-control: The reward responsivity hypothesis, written by Nicholas J. Kelley, Anna J. Finley, Brandon J. Schmeichel was originally published electronically on the publisher's internet portal (currently SpringerLink) on 23 January 2019 with open access.
With the author(s)' decision to step back from Open Choice, the copyright of the article changed on [date the updated version will be/was published] to The Psychonomic Society, Inc. 2019 and the article is forthwith distributed under the terms of copyright.

Publisher's note Springer Nature remains neutral with regard to jurisdictional claims in published maps and institutional affiliations.

The online version of the original article can be found at https://doi.org/ 10.3758/s13415-019-00694-3

Nicholas J. Kelley

nicholasjkelley@gmail.com

1 Department of Psychology, Northwestern University, Swift Hall, 2029 Sheridan Road, Evanston, IL 60208, USA

2 Department of Psychology, Texas A\&M University, College Station, TX, USA 